\title{
Coparentalidade em genitores de bebês com indicativos de dificuldades de inserção escolar
}

\author{
Liana Pasinato \\ Faculdade Meridional - IMED de Passo Fundo - RS \\ Clarisse Pereira Mosmann \\ Universidade do Vale do Rio dos Sinos - RS
}

\begin{abstract}
Resumo
Objetivou-se analisar a coparentalidade em genitores de bebês de idade entre três e oito meses, com indicativos de dificuldades de inserção em escola de Educação Infantil. Realizou-se um estudo exploratório e descritivo, com método de análise de dados qualitativo. Quatro pares de genitores, com idades entre 26 e 40 anos, cujos bebês ingressaram na escola de Educação Infantil logo após o término da licença-maternidade, responderam a um questionário de dados sociodemográficos e a uma entrevista semiestruturada. Os resultados apontam reflexos de características da atualidade neste momento, como as dificuldades das famílias em contar com uma rede de apoio e a valorização das necessidades ou interesses das mães em ajudar na renda familiar, que justificam o ingresso precoce dos bebês na escola. Quanto à coparentalidade, destaca-se entre os genitores uma divisão efetiva de tarefas e o compartilhamento de cuidados com os filhos, mas no processo de inserção escolar ainda são as mães as principais participantes, o que mostra uma heterogeneidade nesses processos.
\end{abstract}

Palavras-chave: Crianças em idade escolar; relações pais-escola; educação infantil.

\section{The families with babies in co-parenting who have indicatives of early school insertion difficulties}

\begin{abstract}
This study aimed to analyze the co-parenting in parents of babies aged between three and eight months, indicative of insertion difficulties in school for early childhood education. We conducted an exploratory and descriptive study with qualitative data analysis method. Four pairs of parents, aged 26 and 40, whose babies entered school for early childhood education right after the end of maternity leave, answered a sociodemographic questionnaire and a semi-structured interview. The results show characteristic of modern reflections at this point, as the difficulties of families to rely on a network of support and appreciation of the needs or interests of mothers to help the family income, justifying the early entry of babies at school. As for co-parenting, stands out among the parents an effective division of labor and the care sharing with their children, but the school inclusion process are still mothers major participants, which shows a heterogeneity in these processes.
\end{abstract}

Keywords: School age children; parent school relationship; early childhood education.

\section{Coparentalidad en genitores de bebitos con indicativos de dificultades de inserción escolar}

\section{Resumen}

Se tuvo por objetivo analizar la relación parental en genitores de bebitos de edad entre tres y ocho meses, con indicativos de dificultades de inserción en escuela de Educación Infantil. Se realizó un estudio exploratorio y descriptivo, con método de análisis de datos cualitativo. Cuatro parejas de genitores, con edades entre 26 y 40 años, cuyos bebitos ingresaron en la escuela de Educación Infantil luego tras el término de la licencia-maternidad, respondieron a un cuestionario de datos sociodemográficos ya una entrevista semiestructurada. Los resultados apuntan reflejos de características de la actualidad en este momento, como las dificultades de las familias en contar con una red de apoyo y la valoración de las necesidades o intereses de las madres en ayudar en la renta familiar, que justifican el ingreso precoz de los bebitos en la escuela. Cuanto a la relación parental, se destaca entre los genitores una división efectiva de tareas y el compartimiento de cuidados con los hijos, pero en el proceso de inserción escolar aún son las madres las principales participantes, lo que enseña una heterogeneidad en esos procesos.

Palabras-clave: Niños en edad escolar; relaciones padres-escuela; educación Infantil. 


\section{Introdução}

Atualmente, não só mães de camadas economicamente desfavorecidas procuram trabalho como recurso para aumentar a renda familiar e se afastam, por esse motivo, do convívio dos seus filhos, mas também mulheres da classe média buscam a inserção profissional como fonte de renda e/ou como realização pessoal (Weber, Santos, Becker, \& Santos, 2006). De acordo com Rapoport (2008), mesmo entre as mães que não trabalham fora algumas têm escolhido colocar o bebê na escola de educação infantil. Essa busca nem sempre é exclusivamente para o cuidado, mas também para a socialização e aprendizagem do bebê e da criança pequena (Rapoport, \& Piccinini, 2004). Além disso, estima-se que essas mães sintam-se, por vezes, sobrecarregadas com as tarefas domésticas e com aquelas relacionadas à maternidade, podendo ver na escola de educação infantil uma oportunidade de satisfazer sua necessidade de obter um tempo para se dedicar a si.

Soma-se a isso o fato de que os cuidados alternativos vêm assumindo um importante papel na vida de pais e mães, uma vez que, além da rotina de trabalho ser intensa para ambos, hoje dificilmente podem contar com rede de apoio social (Seabra, 2007), entendida aqui como as inter-relações que estabelecem com amigos, familiares e a comunidade em geral, as quais, por meio do suporte mútuo, sustentam o sentimento de bem-estar psicossocial (Sluzki, 1996). Necessitam, então, delegar o compartilhamento das funções de cuidados básicos e de educação formal a outras instâncias mais precocemente do que ocorria em outros momentos históricos (Levy, \& Jonathan, 2010). Esse movimento vem antecipando cronologicamente uma etapa de crise evolutiva vital das famílias, já que as crianças estão ingressando na escola logo após o término da licença-maternidade.

$\mathrm{Na}$ literatura não existe consenso com relação ao processo de inserção escolar em termos de definição da caracterização desse período. Para Vitória e Rossetti-Ferreira (1993), pesquisadoras brasileiras, o processo de inserção escolar inicia-se desde o momento em que se estabelece o primeiro contato da escola com a família. A maneira como a família se relacionará com o novo e estranho ambiente será influenciado por essas primeiras impressões. Essas autoras ressaltam que esse processo de inserção não se resume aos primeiros dias, podendo vir a durar meses e só se completar quando a criança, a família e o educador estiverem interagindo de forma integrada na escola de educação infantil. Já para os norte-americanos Bloom-Feshbach e Gaughram (1980), o processo envolve desde o momento de chegada até o final do primeiro mês, ou, segundo Rodriguez (1981), pode ter duração de três a seis meses após o ingresso.

Neste artigo, será considerado como processo de inserção escolar o período que compreende a inserção do bebê na escola até o final do terceiro mês subsequente. Esse processo vem se tornando cada vez mais precoce, também devido à exiguidade dos espaços e moradias urbanas, acrescida da indisponibilidade de tempo de avós e tias. Essas, que antigamente habitavam junto à família e partici- pavam da guarda ou da educação das crianças, hoje estão incorporadas à população ativa (Gravena, 2006; Rizzo, 2010). Identifica-se, então, uma dimensão importante na contextualização deste fenômeno, uma vez que se sabe da relevância do suporte da rede social de apoio à família e ao indivíduo no enfrentamento de transições normativas e não normativas no processo de desenvolvimento. Após o nascimento dos filhos e durante sua inserção escolar, reforça-se a necessidade de os familiares e a comunidade ajudarem os genitores a atravessar esse processo com maiores níveis de saúde (Possatti, \& Diaz, 2002).

Nesse cenário, o pai tem sido demandado a ser mais participante na parentalidade. Ampliou-se seu papel de provedor reprodutivo e financeiro para um pai mais envolvido no cuidado com os filhos e nas tarefas domésticas. Esse envolvimento efetivo é considerado fonte fundamental de apoio, especialmente para mães que cumprem jornada dupla de trabalho, exercendo atividades domésticas e fora do lar (Gravena, 2006).

Consequentemente, em famílias nucleares, o par parental vem sendo, com maior frequência, solicitado a comparecer e acompanhar a criança na escola durante o processo de inserção escolar, tarefa antes desempenhada somente pela mãe. O pai torna-se essencial nesse processo, uma vez que a mãe também está envolvida com suas questões profissionais e a escola de educação infantil precisa da colaboração da família para propiciar um ambiente adequado para o bebê (Gabriel, 2012).

Um dos aspectos relevantes na adaptação do par parental às novas funções concernentes ao período de inserção escolar é a sincronia na divisão das tarefas educacionais, o que constitui o conceito de coparentalidade, que abrange a coordenação de dois adultos no cuidado e desenvolvimento de uma criança (McHale, Kuersten-Hogan, \& Rao, 2004). A aliança coparental é apontada pelas pesquisas como um dos elementos essenciais para a funcionalidade sistêmica da família, e pode ser associada a trajetórias desenvolvimentais com melhores níveis de adaptação e bem-estar psicossocial das crianças (Lamela, Nunes-Costa, \& Figueiredo, 2010).

Dados nacionais (Mosmann, Einsfeld, Silva, \& Terres-Trindade, 2012) indicam que a coparentalidade está associada a sintomas internalizantes e externalizantes dos filhos, o que justifica a importância de os casais terem a capacidade de negociar suas práticas coparentais, assim como de se apoiarem e sustentarem-se mutuamente. Por outro lado, casais com maiores níveis de conflito coparental tendem a expor suas discordâncias coparentais e, consequentemente, competir nessas funções.

Assumindo-se, então, a importância da coparentalidade no desenvolvimento dos filhos, questiona-se: como ela se expressa no período de inserção escolar?

Nesse sentido, tanto no contexto nacional como no internacional, identifica-se uma lacuna nos estudos sobre inserção das crianças na escola que enfocam o papel do par parental. As pesquisas investigam majoritariamente as relações entre as mães, as crianças e as cuidadoras, e apontam como principais conclusões que a qualidade do processo 
está relacionada com a forma como a mãe lida com esse momento (Almeida, 2006; Bonds, \& Gondoli, 2007; Lopes, Alfaya, Machado, \& Piccinini, 2005; Mondin, 2005; Silva, Fernandes, Veríssimo, Shin, Vaughn, \& Bost, 2008). Estudos nacionais (Rapoport, 2008; Vitória, \& Rossetti-Ferreira, 1993) ressaltam que a maneira como a família, em especial a mãe, lida com a entrada da criança na escola de educação infantil tem impacto sobre a reação da criança à inserção, pois muitas das emoções que os filhos identificam na genitora são expressas em seu comportamento.

Segundo Rizzo (2010), quando a mãe e a criança enfrentam muitas dificuldades em se afastar, a criança pode apresentar sintomas físicos como febre, vômitos, diarreias, tosse nervosa, bronquite de fundo nervoso e alergias. Outros indicativos de dificuldades relacionadas à inserção escolar são o fato de a criança apresentar, por um período igual ou superior a três meses, as seguintes características: problemas de sono, problemas relacionados à alimentação, ataques de raiva e/ou choro, chupar o dedo, ficar dependente de um brinquedo e/ou mamadeira e ter pesadelos (Brazelton, \& Sparrow, 2003). Também a resistência do bebê a ir embora ao final do dia deve ser considerada. Algumas vezes, pais e educadoras interpretam como um sinal de que o bebê está gostando de ficar na escola, quando na realidade pode ser o contrário: uma demonstração de sofrimento por parte deste (Rodriguez, 1981).

É possível, também, que o grande investimento emocional que a criança realiza durante esse período a torne menos resistente a infecções. Alguns pediatras suspeitam do alto índice de doenças verificado na época do ingresso na escola de educação infantil; contudo, outros fatores não podem ser ignorados, como a primeira exposição da criança a grupos estranhos maiores e a sua baixa idade para a escola de educação infantil, a que corresponde um menor grau de resistência imunológica (Andrade, \& Rodrigues, 2005). De qualquer forma, Rizzo (2010) refere que a mãe, principalmente, deve ser esclarecida sobre todos os problemas esperados com a inserção escolar e sobre qual o seu papel como agente ativo nesse processo.

Weber, Santos, Becker e Santos (2006) buscaram identificar, por meio de um questionário com perguntas abertas e fechadas, os motivos e sentimentos de 67 mães provenientes de níveis socioeconômicos distintos, que deixavam seus filhos em escolas de educação infantil. Os dados revelaram que deixar os filhos nessas instituições ainda provoca um forte conflito. O fato de deixar o filho em escolas de educação infantil, principalmente se por necessidade, traz consequências positivas como, por exemplo, realização profissional e/ou remuneração financeira para essas muIheres, porém o cuidado dos filhos por outras pessoas que não a mãe ainda é visto, culturalmente, como inadequado e passível de consequências negativas ao desenvolvimento da criança. Essas concepções terminam por provocar sentimentos de medo e de insegurança na maioria das mães que participaram da pesquisa. Cabe ressaltar a ainda existente cobrança por parte da sociedade no sentido de que a mulher volte a exercer integralmente sua função de mãe e dona de casa. Isso também pode estar associado a esse conflito e ao sentimento de culpa dessas mães, uma vez que estas mulheres aprenderam que os cuidados maternos são insubstituíveis (Badinter, 2011).

Os resultados desses estudos sustentam o ingresso na escola como um período de crise, e ainda que neste momento o foco seja o papel da mãe, assume-se, de uma perspectiva sistêmica, que esses processos demandam uma readaptação de papéis e de funções também da figura paterna, especialmente do par parental. Se essa reorganização ocorre com menores níveis de funcionalidade, em se tratando de bebês, os sintomas tendem a ser psicossomáticos (Minuchin, Nichols, \& Lee, 2009).

Essas reações durante a inserção da criança na escola infantil podem variar, haja vista que dependem da idade, do tipo de relacionamento entre ela e seus pais, da maneira como estes concebem a escola de educação infantil e de como a criança será recepcionada e acolhida por esta (Vitória, \& Rossetti-Ferreira, 1993).

Em pesquisa realizada com 41 educadoras de escolas de educação infantil de Porto Alegre, com o objetivo de examinar como educadoras de escolas municipais e particulares caracterizavam a inserção de bebês de quatro a cinco meses e oito a nove meses, Rapoport e Piccinini (2001b) observaram que apenas um terço destas enfatiza a importância de os genitores permanecerem nos primeiros dias. Isto significa que a presença de um familiar não é procedimento usual para todas as escolas de educação infantil. Além disso, identifica-se que algumas famílias resistem a fazer o processo de inserção, alegando que não têm tempo ou não podem devido ao trabalho. Faz-se necessário considerar as dificuldades das escolas para encontrar algum familiar com tempo, principalmente os genitores, para ser a referência de que a criança precisa, uma vez que a grande maioria está envolvida com o trabalho.

Nesse contexto, identificam-se os inúmeros desafios a serem enfrentados na atualidade pelas famílias nucleares no momento da entrada dos filhos para a escola de educação infantil. A escassez de rede social de apoio e as múltiplas demandas profissionais e pessoais das mães exigem maior participação do pai, antecipam este momento e conferem ainda mais complexidade a este período de crise do ciclo evolutivo vital familiar. A articulação entre essas relações pode expressar-se em dificuldades dos filhos durante esse período. Dessa forma, o presente artigo objetivou analisar a coparentalidade no processo de inserção escolar de bebês de idade entre três e oito meses que apresentem dificuldades de ingressar na escola de educação infantil.

\section{Método}

\section{Participantes}

Participaram deste estudo quatro casais de duplo trabalho, com idades entre 26 e 40 anos, com filhos que ingres- 
Tabela 1. Tabela de Caracterização das famílias

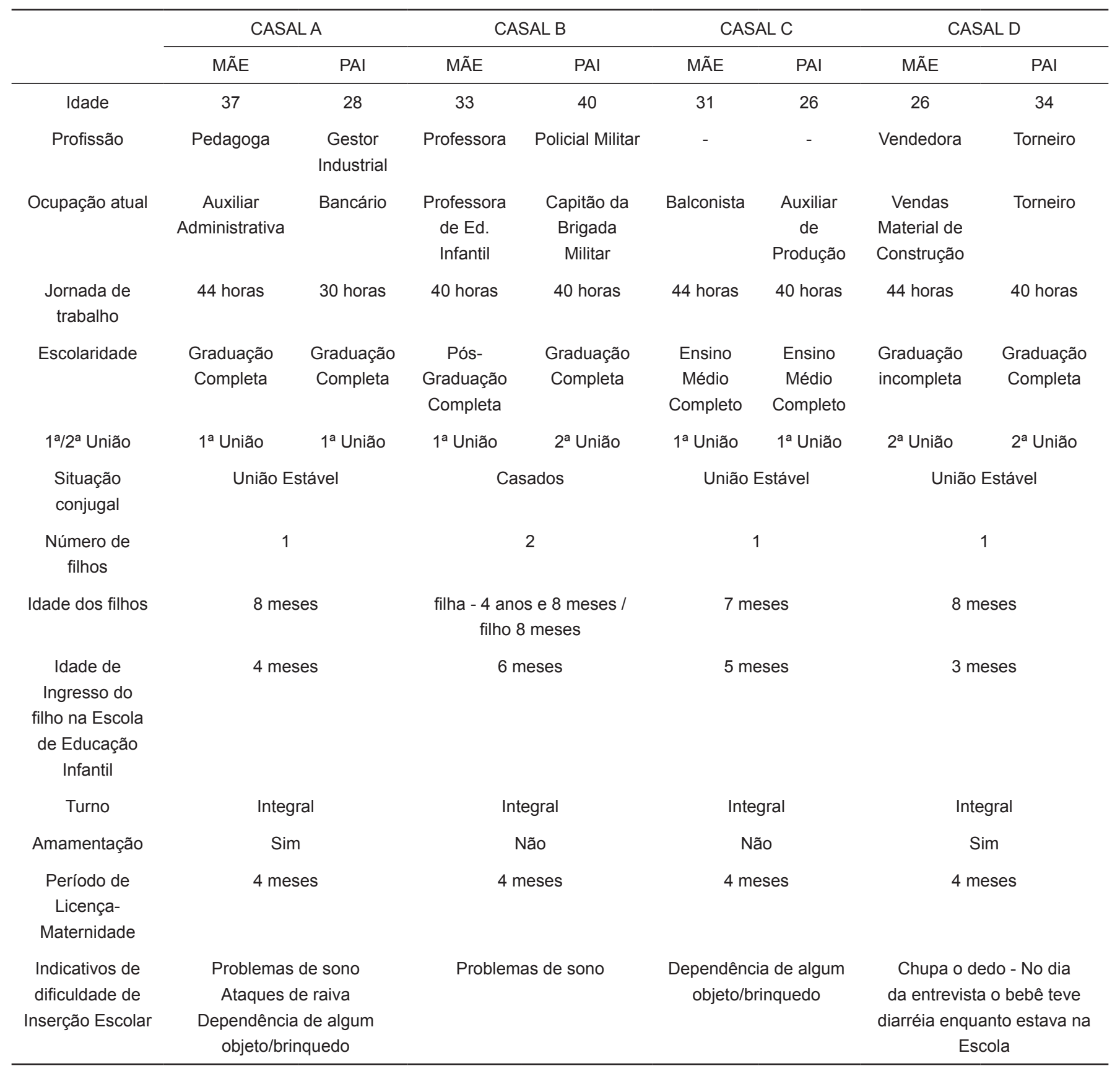

saram na escola de educação infantil logo após o término da licença-maternidade e estavam apresentando, segundo a escola, dificuldades na inserção escolar.

\section{Procedimentos de coleta de dados}

Realizou-se contato com escolas particulares do município de Erechim/RS, as quais indicaram as famílias que, segundo avaliação da escola, estavam passando por dificuldades no processo de inserção escolar. Essas famílias foram contatadas e convidadas a participar da pesquisa. Uma vez aceito o convite, foi agendada uma entrevista no local de maior conveniência para a família.

Primeiramente, foi realizada uma entrevista com os dois genitores e, ao final desta, foi agendado um novo encontro individual com cada genitor, quando foi repetida a mesma entrevista. Nesse momento, buscou-se propiciar um espaço individual a cada genitor para que ambos avaliassem as dificuldades associadas à coparentalidade e ao processo de inserção escolar de seus filhos. 


\section{Instrumentos}

Foram utilizados os seguintes instrumentos: 1- ficha de dados sociodemográficos; 2- entrevista sobre coparentalidade: roteiro desenvolvido pelo Núcleo de Estudos e Pesquisas em Transtorno do Desenvolvimento, UFRGS (NIEPED, 2006).

A entrevista foi adaptada aos objetivos do presente estudo, enfocando a inserção escolar. $O$ instrumento foi constituído por dezoito perguntas, em oito dimensões: pergunta introdutória; parentalidade; relacionamento com o filho (a); apoio mútuo; compartilhamento de cuidados; práticas educativas/valores/expectativas; engajamento em atividades com o filho (a); engajamento em atividades com a família. Em relação ao procedimento de análise de dados, todas as entrevistas foram gravadas e, posteriormente, transcritas e analisadas por meio do método da análise de conteúdo (Bardin, 1977).

\section{Resultados e discussão}

Os resultados serão apresentados a partir de um eixo temático denominado inserção escolar, e de categorias elaboradas a partir da análise de conteúdo das entrevistas realizadas com os genitores.

\section{Inserção escolar}

Neste eixo identificaram-se as questões referentes ao período de inserção escolar dos filhos.

\section{Motivos da inserção escolar}

Esta categoria abrange os motivos que levaram os pais a inserir a criança na escola de educação infantil.

Identifica-se que, em função de diferentes necessidades, os casais tiveram que recorrer aos cuidados oferecidos pelas escolas de educação infantil. Primeiramente, foram pensadas alternativas como pagar uma babá e/ou ficar em casa, que acabaram sendo desconsideradas por esses genitores, pois optaram pelo que acreditavam ser uma melhor escolha para eles e para o bebê, conforme a fala a seguir: “... por uma opção, pagar uma tatá pra cuidar, sabe como é, a gente não tem confiança na pessoa que vai botar dentro da tua própria casa" (pai C).

Destaca-se a questão financeira: “... a princípio a gente tinha raciocinado de eu trabalhar só de tarde, cálculo e puxa e soma e diminui... eu vou ter que voltar o dia inteiro... eu tô longe do meu filho tempo demais do que eu gostaria, mas eu posso dar coisas pra ele..." (mãe D).

Para algumas famílias, a socialização e a aprendizagem do bebê foram mais relevantes (Rapoport \& Piccinini, 2004): “... uma amiga me dizia: "mas por que tu tá deixando na escolinha? Por que tu não deixa com a tua mãe?”. Eu acho que na escolinha ela vai desenvolver bem mais..." (mãe A).

Essas falas corroboram os dados da literatura (Levy, \& Jonathan, 2010; Weber, \& cols., 2006) de que as mães buscam o trabalho também para aumentar a renda familiar, sendo, então, necessário que os cuidados básicos e a educação dos seus filhos sejam delegados às escolas de educação infantil, durante suas jornadas laborais. Cabe ressaltar que, apesar de haver um conflito inicial entre a questão financeira e colocar o bebê na escola de educação infantil, deu-se prioridade à primeira, o que pode ser apontado como uma mudança da atualidade que tem reflexos na decisão referente a este momento. Anteriormente, a dinâmica familiar e social impelia as mães a ficarem em casa com os filhos, abdicando de uma vida profissional, enquanto as mães deste estudo optaram por continuar inseridas no mercado de trabalho, embora isso gerasse um sofrimento por se afastarem logo após o término da licença-maternidade. Cabe ressaltar que esses dados foram trazidos pelo par parental, indicando haver um consenso entre ambos acerca da decisão.

\section{Rede social de apoio}

Esta categoria contempla as dificuldades dos pais em dispor de uma rede social de apoio que pudesse auxiliá-los nesse momento de inserção escolar dos filhos, coincidindo com o que os autores Gravena (2006), Levy, \& Jonathan (2010) e Rizzo (2010) referem em seus estudos, apontando que atualmente as avós e/ou tias, que anteriormente auxiliavam nos cuidados com as crianças, estão também inseridas na população economicamente ativa e/ou vivem distantes.

Nas falas a seguir evidencia-se que, se os pais pudessem e/ou tivessem com quem deixar seus filhos, não os teriam inserido na escola de educação infantil logo após o término da licença-maternidade: “... a gente pensa várias vezes em ter alguém em casa pra retirar ele da escola... a gente não pode contar com uma pessoa que possa faltar, daí onde que ele vai ficar..." (mãe B); "...a minha mãe mora fora do estado.." (pai D).

Cabe destacar que em apenas uma das famílias observa-se o contrário: os cônjuges relataram ter uma rede social de apoio: os avós da criança. Fica evidente, a partir dos seguintes relatos, que colocar o bebê na escola de educação infantil foi uma opção dos pais: “...o sogro e a sogra que moram em cima, então se tem uma situação que os dois estão ocupados... ela vai lá, brinca com o vô e com a vó" (pai A).

Deve-se considerar que a escassez de rede social de apoio se expressa como falta de opção para a maioria dos pais entrevistados, enquanto outros optaram pela socialização da criança na escola, uma vez que teriam uma rede social de apoio com a qual poderiam contar para o período. Isso pode estar indicando maior liberdade por parte de algumas famílias em fazer opções sobre a vida dos filhos sem estarem tão amarradas às concepções sociais e familiares de que a única alternativa saudável seria o bebê estar com 
a mãe ou familiares durante o período pós-licença-maternidade.

\section{Sentimentos dos genitores}

Esta categoria compreende os sentimentos que os pais e as mães expressaram com maior frequência com relação ao período de inserção escolar dos filhos. Dentre eles, destacam-se o conflito entre voltar ao trabalho e a maternidade, a culpa pela escolha e as principais preocupações.

Relacionado aos sentimentos das mães, surge o conflito entre o trabalho e a maternidade, que pode ser ilustrado a partir das seguintes frases: "... passou pela minha cabeça, em alguns momentos, abandonar tudo e ficar só com ela..." (mãe A); " ...se tivesse optado por ficar em casa, num momento eu também não ia tá feliz... a gente quer tá em contato com outras pessoas, trabalhando, ter o dinheiro...não ficar fora do mercado...e às vezes tu tá com a criança ali e daí tá triste" (mãe A).

Esse resultado coincide com os dados encontrados pelos autores Weber e cols. (2006), no sentido de que deixar os filhos aos cuidados da escola de educação infantil ainda provoca um forte conflito para a maior parte das mães. Culturalmente, os cuidados maternos vieram sendo declarados como os melhores para as crianças. Quando a mãe passa a trabalhar fora, surge uma cobrança da sociedade para que ela retorne ao cuidado do lar e dos filhos. Esse fator pode desencadear na mãe um sentimento de culpa, por pensar que não está cumprindo com o seu papel (Badinter, 2011). As seguintes falas corroboram os resultados desses estudos: “... depois vem a situação de culpa... tu vê tua filhinha assim chorando, ai eu saía de lá e começava a chorar, eu pensava assim: ela vai se sentir abandonada, eu tô abandonando ela, eu vou traumatizar minha filha.." (mãe A).

Os dados também apontam sentimentos ambivalentes dos pais. Esses sentimentos são expostos por meio das preocupações relatadas nas seguintes frases, notando-se também o discurso de uma mãe incluindo o pai nesse momento: "Foi mais difícil acho pra nós... como eu sou profe também, eu tenho uma resistência em mandar muito novo pra escola. Se pudesse ficar em casa ficaria” (mãe B); "a preocupação minha foi como ela fosse cuidada na escolinha, porque vai saber se cuidam bem dos filhos da gente.." (pai C).

Cabe ressaltar que dados como esses são escassos na literatura. Os estudos que não se referem somente à mãe, neste período, utilizam o termo pais englobando o pai e mãe, não diferenciando os sentimentos dos genitores homens.

\section{Reações ante a inserção escolar}

Esta categoria contempla os conteúdos referentes à forma como o par parental lida com as dificuldades inerentes ao período de inserção escolar.
Os relatos abaixo corroboram, em parte, os dados encontrados pelos autores Vitória e Rossetti-Ferreira (1993) e Rapoport (2008), os quais ressaltam que a maneira como a família, em especial a mãe, lida com a entrada da criança na escola de educação infantil tem impacto sobre a reação da criança à inserção, pois muitas das emoções que os fiIhos identificam na genitora são expressas em seu comportamento. Nas falas dos participantes identificam-se reações não só das mães, mas também dos pais: "A entrada dele na escolinha... foi mais de sofrimento dos pais, se ele vai ser bem cuidado, se não vai ficar doente, se ele vai ficar adaptado com os professores" (mãe B); "A criança quando nasce ela já sente o estado que o pai e a mãe estão; quanto mais tranquilidade se demonstrar pra eles, mais eles ficam mais tranquilos..." (pai D).

Não se identifica uma diferenciação no sofrimento associado aos papéis de mãe e pai, mas sim, como o par parental, conjuntamente, precisa lidar com essas dificuldades para enfrentar este momento de crise.

Esses resultados parecem indicar mudanças no comportamento familiar que ainda não foram estudadas suficientemente no contexto nacional, uma vez que as pesquisas centram-se, em sua maior parte, nos sentimentos das mães durante este processo. Nesse sentido, nossos achados sustentam em parte os estudos que mostram a importância do papel da mãe neste período (Almeida, 2006; Bonds \& Gondoli, 2007; Lopes \& cols., 2005; Mondin, 2005; Silva \& cols., 2008), mas apontam de forma clara que, para as famílias deste estudo, este sofrimento é de ambos, do par parental que compartilha esses sentimentos.

\section{Indicativos de dificuldades de inserção escolar dos filhos}

Esta categoria compreende os sintomas apresentados pelas crianças durante o período de inserção escolar, que são avaliados, principalmente pela escola, como indicativos de que a criança está com dificuldades nesse processo.

Cabe destacar que, quando na entrevistas os pais os pais foram questionados sobre os sintomas apresentados pelos filhos durante o processo de inserção escolar, a maioria não conseguiu identificá-los; mas no momento em que se fez o mesmo questionamento a partir de uma lista que correspondia aos dados sociodemográficos e clínicos dessas famílias, estas puderam reconhecer algumas das características nos seus filhos, conforme ilustra a tabela 1. Alguns relatos condizem com a literatura: “... o cocozinho aumentou... de repente ela começou estranhar, não ir no colo de todo mundo, ham, tava assim mais apegada a mim. Ela tem a bonequinha dela, que daí ela ficava mais juntinho" (mãe A); "...ele chora da escola até em casa por causa do bebê conforto, ele quer o colo meu, ele sente muita necessidade de sair da escola e estar grudado em mim" (mãe B).

Segundo Rizzo (2010), a criança também pode vir a apresentar, durante o processo de inserção escolar, alguns sintomas físicos. Essas somatizações podem ser decor- 
rentes de um intenso sofrimento vivenciado pela criança e pelos seus pais no momento da separação que esse período exige. Os relatos dos pais corroboram esses dados: “... tinha um desconforto...dormia e acordava...aí a gente acabou retomando a medicação, e agora ele tá dormindo melhor" (pai B); "...a questão de saúde, respiratória, ele tem bastante dificuldade respiratória e...refluxo" (mãe B).

O grande investimento emocional que a criança faz durante o período de inserção escolar pode torná-la menos resistente às infecções (Andrade \& Rodrigues, 2005; Rizzo, 2010). Os relatos corroboram esses postulados: “... único problema da escolinha é porque um tá doente, todos vão ficar..” (mãe B); “... ele já pegou uma gripe, uma epongina, tipo uma afta na garganta, e isso ele pegou de outras crianças" (pai B).

A resistência do bebê a ir embora ao final do dia também deve ser considerada como um indicativo de que a criança pode estar apresentando algum desajustamento à nova situação (Rodriguez, 1981): "Eu fico bem feliz assim, de ver a $V$. às vezes ir de braço aberto pra professora, e depois na hora de ir buscar também sair sorrindo, ou às vezes não querer vir..." (pai A);”... meu filho gosta de ir...até ele dá uma reclamadinha pra vir pra casa..." (pai D).

Algumas vezes pais e educadoras interpretam esse gesto como um sinal de que o bebê está gostando de ficar na escola de educação infantil, quando poderá ser exatamente o contrário, ou seja, uma demonstração de sofrimento por parte deste (Rodriguez, 1981).

Os resultados dos dados colhidos junto aos genitores deste estudo corroboram os dados encontrados na literatura (Brazelton, \& Sparrow, 2003; Rizzo, 2010; Rodriguez, 1981). Esses resultados configuram o ingresso na escola como um período de crise que, se não é vivido com maiores níveis de funcionalidade, pode levar a criança a desenvolver sintomas decorrentes da não adaptação.

Embora tenha variado o tempo de inserção escolar de cada criança deste estudo, para se afirmar que não houve adaptação faz-se necessário fazer uma reavaliação do tempo, pois somente em dois dos casais a adaptação ocorreu acima do tempo considerado pela literatura como esperado. Rodriguez (1981) entende que esse período pode durar até os seis meses. São os bebês das famílias "A" e "D" os que apresentam mais indicativos de dificuldades de inserção escolar; porém, somente se os sintomas persistirem por mais tempo poderão configurar uma dificuldade maior, da família e da criança, de adaptar-se a essa condição.

\section{Coparentalidade na inserção escolar}

Nesta categoria são apresentadas as questões referentes à coparentalidade e ao compartilhamento de cuidados em relação à inserção escolar. Os relatos que seguem coincidem com dados da pesquisa de Gravena (2006), que mostra que o pai está sendo demandado a ser mais participante nas questões ligadas à coparentalidade: $A P$ de tarde tá em aula, ai é difícil atender o telefone, se tem algum problema ligam pra mim" (pai B).

Os pais sabem da importância de os dois genitores participarem, porém isso ainda não acontece de forma natural, tanto que as mães, quando se dão conta de que estão mais envolvidas, referem abrir espaço para que eles também participem. Assim, às vezes os pais referem dividir essas tarefas, outras vezes parece que o fazem se houver necessidade. A falta de tempo dos pais, devido ao trabalho, é o que, segundo eles, justifica esta dinâmica. A mãe é quem arruma o tempo necessário para dar conta das demandas da criança: "Ele leva na escolinha quando tem que levar, busca se precisar, preocupado com as coisas, com o desenvolvimento dela na escolinha... e quando tem que ligar pra escola, pra alguma coisa ou outra, normalmente tem sido eu assim né..." (mãe A); "...não que seja determinado, mas imposto pelos horários...a V leva...vai ao meio dia, porque eu não posso ir na escolinha, e daí por causa do meu horário eu busco..." (pai A).

A partir dos relatos, fica evidente que os casais participantes deste estudo se dividem em dois tipos: os que dividem igualmente as tarefas relacionadas à coparentalidade e aqueles que dividem de forma menos igualitária, ou seja, quando houver uma demanda. Esses dados sustentam que, mesmo em núcleos intactos, coexistem atualmente diferentes formas de organização das funções coparentais. Como o objetivo do estudo é analisar a coparentalidade em famílias intactas e a maior parte dos estudos acerca desse conceito centra-se no seu exercício após o divórcio, destaca-se a relevância desses achados no contexto nacional.

Faz-se necessário considerar que, no casal $\mathrm{C}$, em função de a criança ter trocado de escola, ocorreu uma mudança que fez com que o pai assumisse mais as responsabilidades com ela. Antes disso, a mãe era quem tomava conta da maior parte das tarefas referentes aos cuidados da filha, como se constata na fala a seguir: "... ela apronta a I, espera a besta chegar... que ela trocou de escola...e de noite quando ela chega...eu já tô em casa, eu pego ela, dou banho, como eu tô antes em casa, ela chega, fica um pouquinho com ela, e ela logo em seguida vai dormir" (pai C).

No discurso do casal $D$, essa divisão aparece de forma menos igualitária. A mãe tem tomado a frente com relação à maior parte das atividades referentes ao filho: “... vou buscar ele na escola, volto pra casa, o pai assistindo TV...o J toma banho no colo do H e eu já deixo a mamadeira pronta, se ele tá muito cansado ele já dorme..." (mãe D).

Identifica-se, a partir dos relatos, que as mães deste estudo têm a participação e a colaboração dos pais nos cuidados dos filhos durante esse período de inserção escolar. Sugere-se que há uma divisão, mesmo que alguns desses pais participem mais quando há uma necessidade e/ou oportunidade, pois parece ficar claro que, se for preciso ou se eles tiverem maior tempo livre do que a mãe, eles se ajustam aos deveres coparentais.

Existem, assim, diferentes formas de organização e cooperação coparental nos casais desta pesquisa. De forma geral, pode-se apontar que não há altos níveis de conflito 
coparental, assim como relativos níveis de acordo coparental. Segundo a literatura (Mosmann \& cols., 2012), menores índices de conflito coparental estariam vinculados a melhores níveis de saúde da família. Considerando-se o critério utilizado neste estudo para caracterizar dificuldades de inserção escolar, dois bebês confirmam o quadro. Pode-se pensar que a coparentalidade está-se expressando como fator protetivo para estas famílias.

Cabe ressaltar que foram as escolas que apontaram estas crianças como tendo dificuldades, e que se faz necessário aguardar um maior período de tempo para avaliar se as dificuldades persistem.

\section{Inclusão do par parental na escola}

Esta categoria compreende a participação dos pais durante o processo de inserção escolar dos filhos na escola de educação infantil. A literatura aponta que é fundamental a presença dos pais ou de algum familiar no estabelecimento dos vínculos com as educadoras e com outras crianças (Rapoport \& Piccinini, 2001a), porém são poucas as educadoras que enfatizam a importância da presença de ambos os genitores nos primeiros dias de inserção escolar dos filhos (Rapoport \& Piccinini, 2001b), dado que está de acordo com os do presente estudo, uma vez que somente o casal "A" esteve junto nesse processo: “... nos primeiros dias, ele conseguiu jogar os horários para ir lá, e fica e meio dia enquanto eu dava mama, fica junto pra vê ela, sabe..." (mãe A).

A partir dos relatos $B, C$ e D, abaixo, pode-se observar que as mães é que acompanharam a inserção escolar de seus filhos, resultados que vem ao encontro do enfoque majoritário dado pelas pesquisas ao papel da mãe. Deve-se considerar que os pais geralmente estão trabalhando e não podem acompanhar as mães nesse processo, pois somente estas têm direito à licença-maternidade: "Eu fiz adaptação dele... foi uma semana (mãe B); ... teve adaptação, né, que eu levei ela uns dias...." (mãe $\mathrm{C}$ ); "e as primeiras duas semanas eu fiquei com ele na escola” (mãe D).

Outro fator que pode estar relacionado à maior presença das mães durante esse período é a amamentação. Duas delas estavam amamentando durante a inserção. De qualquer forma ainda que essa situação exija a presença da mãe, não deveria excluir a participação dos pais, como observado no casal A.

Nesse contexto, nota-se que os pais dão suporte ao processo, mas quem acompanha a inserção da criança na escola é a mãe. Somente um casal realizou o processo conjuntamente. Depois que a criança já está adaptada, os pais parecem inserir-se de forma mais efetiva. Chama a atenção este resultado, uma vez que os genitores masculinos deste estudo mostraram-se envolvidos e participativos nas funções coparentais. Não é possível inferir, a partir dos resultados deste estudo, se isso ocorre por falta de incentivo das escolas, pela presença do pai, ou se ainda reflete uma concepção social de que é a mãe quem deve assumir esse processo, mas provavelmente se deve a todos estes fatores; entretanto, o fato de um dos casais ter participado conjuntamente pode estar indicando uma modificação nesse padrão.

\section{Considerações finais}

Identificou-se que, motivados pela questão financeira e também por um melhor desenvolvimento da aprendizagem e da socialização dos bebês, os casais deste estudo decidiram inserir seus filhos em escolas de educação infantis após o término da licença-maternidade. Para a maior parte desses casais, esse foi o reflexo da ausência de uma rede social de apoio, mas para um deles, a decisão se deu por opção, já que havia quem poderia, na família, auxiliar nos cuidados com os filhos.

Esses resultados indicam algumas mudanças da atualidade que têm reflexos neste processo, pois levam os genitores a se reorganizarem em função das demandas do trabalho, da divisão de tarefas e do compartilhamento de cuidados no que diz respeito à participação de ambos os pais em funções anteriormente atribuídas somente à mãe. Cabe ressaltar que, apesar das preocupações e dos sentimentos ambivalentes, a concepção cultural de que os cuidados para com o bebê deveriam ser desempenhados pela mãe ou por familiares parece já não ter um peso tão significativo nas escolhas desses casais.

Nota-se, a partir dos relatos, que o par parental enfrentou conjuntamente as dificuldades relacionadas a esse período. Mesmo que os pais não acompanhassem a mãe até a escola, sentiram e relataram as mesmas angústias e preocupações. Esses dados indicam um pai muito mais atuante. Os casais deste estudo dividem as tarefas e também o compartilhamento de cuidados com os filhos, embora de forma não totalmente igualitária.

Somente um dos casais acompanhou conjuntamente a entrada do filho na escola. Não se sabe se isso ocorre pela dificuldade das famílias ou se pelo fato de as escolas de educação infantil não convidarem o par parental para participar do processo de inserção escolar dos filhos, frisando, inclusive, sua importância. Cabe destacar que a expectativa inicial, principalmente das escolas, era de que havia relação entre a dificuldade dos pais em desempenhar a coparentalidade durante esse período e a das crianças em inserir-se na escola. Essa hipótese não se confirmou, provavelmente porque existem outros estressores que podem estar comprometendo esse processo, como, por exemplo, o fato de a criança ficar muito tempo longe dos genitores, já que permanece na escola o dia todo.

Identifica-se, então, a necessidade de que sejam realizados outros estudos, já que os resultados aqui demonstrados estão circunscritos a uma pequena amostra de famílias nucleares, a qual foi de difícil acesso. As escolas de educação infantil apontavam as famílias que estavam passando por dificuldades de inserção escolar, segundo suas avaliações, e estas se negavam a participar da pesquisa, alegando falta de tempo. Diante disso, sugere-se a realização de estudos quantitativos, com maior número de 
participantes e em outros contextos nacionais, e novos estudos qualitativos de caráter longitudinal, estudos de caso e observação, para que se possa conhecer de forma mais aprofundada o funcionamento das escolas, das crianças e de casais e famílias de distintos arranjos familiares neste processo. Ressalta-se que foram estudadas apenas famílias nucleares devido ao objetivo de investigar a coparentalidade em núcleos intactos, algo pouco estudado no contexto nacional; entretanto, sabe-se que esses arranjos representam atualmente apenas uma parte do universo da diversidade familiar.

Justifica-se o presente estudo, assim como investigações futuras, pela relevância e pela atualidade da temática, uma vez que o estilo de vida das famílias vem demandando cada vez mais a necessidade de escolas de educação infantil em turno integral, realidade não mais restrita às capitais. Esses achados podem contribuir para reafirmar, para as escolas, a importância da participação do par parental durante o processo de inserção. Nota-se uma evolução das escolas nesse sentido, mas algumas ainda reivindicam somente o acompanhamento da mãe. Sugere-se que sejam desenvolvidas intervenções efetivas junto às escolas de educação infantil no sentido de trabalharem com as educadoras a fundamental importância de ambos os genitores acompanharem esse período de inserção escolar. Espera-se que essas iniciativas possam contribuir para a consolidação da participação de ambos os genitores no processo de inserção escolar de seus filhos.

\section{Referências}

Almeida, L. S. (2006). A cognição social e a construção da relação educador-bebê na creche. Ciências \& Cognição, 7, 42-48.

Andrade, M. A. C., \& Rodrigues, M. M. P. (2005). Indicadores de adoecimento antes e após o ingresso da criança na creche. Revista Brasileira de Desenvolvimento Humano, 15(2), 13-21.

Badinter, E. (2011). O Conflito: a mulher e a mãe. Rio de Janeiro: Record.

Bardin, L. (1977). Análise de Conteúdo. Lisboa: Edições 70.

Bloom-Feshbach, S., Bloom-Feshbach, J., \& Gaughran, J. (1980). The child's tie to both parents: Separation paterns and nursery school adjustment. American Journal of Orthopsychiatry, 50, 505521.

Bonds, D. D., \& Gondoli, D. M. (2007). Examining the process by which marital adjustment affects maternal warmth: the role of coparenting support as a mediator. Journal of Family Psychology, 21, 288-296.

Brazelton, B., \& Sparrow, J. (2003). 3 a 6 anos: Momentos Decisivos no Desenvolvimento Infantil. Porto Alegre: Artmed.
Gabriel, M. G. (2012). Transformações no envolvimento paterno ao longo dos seis primeiros meses do bebê na creche. Dissertação de Mestrado não publicada. Universidade Federal do Rio Grande do Sul, Porto Alegre-RS.

Gravena, A. C. (2006). Retorno ao trabalho após o nascimento de um filho: percepções de professoras sobre sua experiência. Dissertação de Mestrado não publicada. Universidade Federal de São Carlos, São Carlos-SP.

Lamela, D., Costa, R. N., \& Figueiredo, B. (2010). Modelos Teóricos das Relações Coparentais: revisão crítica. Psicologia em Estudo, 15(1), 205-216.

Levy, L., \& Jonathan, E. G. (2010). Minha família é legal? A família no imaginário infantil. Estudos de Psicologia, 27(1), 49-56.

Lopes, R. C. S., Alfaya, C., Machado, C. V., \& Piccicini, C. A. (2005). "No início eu saía com o coração partido...": as primeiras situações de separação mãe-bebê. Revista Brasileira de Desenvolvimento Humano, 15(3), 26-35.

McHale, J. P., Kuersten-Hogan, R., \& Rao, N. (2004). Growing Points for Coparenting Theory and Research. Journal of Adult Development, 11(3), 221-234.

Minuchin, S., Nichols, M. P. \& Lee, W. (2009). Famílias e Casais: do sintoma ao sistema. Porto Alegre: Artmed.

Mondin, E. M. C. (2005). Interações afetivas na família e na préescola. Estudos de Psicologia 10(1), 131-138.

Mosmann, C., Einsfeld, P., Silva, A. M., \& Terres-Trindade, M. (2012). Interação conjugal, coparental, parental e sintomas internalizantes e externalizantes dos filhos: resultados preliminares. Trabalho apresentado no Segundo Congresso de Iniciação Científica e PósGraduação (CICPG): São Leopoldo, RS.

Núcleo de Estudos e Pesquisas em Transtorno do DesenvolvimentoNIEPED, (2006)._Entrevista sobre coparentalidade. Porto Alegre: UFRGS (material não publicado).

Possatti, I. C., \& Dias, M. R. (2002). Multiplicidade de Papéis da Mulher e seus Efeitos para o Bem-Estar Psicológico. Psicologia: Reflexão e Crítica, 15(2), 293-301.

Rapoport, A. (2008). Adaptação de bebês à creche: a importância da atenção de pais e educadores. Porto Alegre: Mediação.

Rapoport, A., \& Piccinini, C. A. (2001a). O ingresso e Adaptação de Bebês e Crianças Pequenas à Creche: Alguns Aspectos Críticos. Psicologia: Reflexão e Crítica, 14(1), 81-95.

Rapoport, A., \& Piccinini, C. A. (2001b). Concepções de Educadoras Sobre a Adaptação de Bebês à Creche. Psicologia: Teoria e Pesquisa, 17(1), 69-78. 
Rapoport, A., \& Piccinini, C. A. (2004). A escolha do cuidado alternativo para o bebê e a criança pequena. Estudos de Psicologia, 9(3), 497-503.

Rizzo, G. (2010). Creche: organização, currículo, montagem e funcionamento. Rio de Janeiro: Bertrand Brasil.

Rodriguez, D. T. (1981). Infant day care: How very young children adapt. Children Today, 10-12.

Rossetti-Ferreira, M. C., Amorim, K. S., \& Vitória, T. (1994). A creche enquanto contexto possível de desenvolvimento da criança pequena. Revista Brasileira de Crescimento e Desenvolvimento Humano, 4(2), 35-40.

Seabra, K. C. (2007). A paternidade em famílias urbanas: uma análise da participação do pai na creche-escola e nos cuidados com o filho. Tese de Doutorado não publicada. Universidade do Estado do Rio de Janeiro, Rio de Janeiro-RJ.
Silva, F., Fernandes, M., Veríssimo, M., Shin, N., Vaughn, B. E., \& Bost, K. K. (2008). A concordância entre o comportamento de base segura com a mãe nos primeiros anos de vida e os modelos internos dinâmicos no pré-escolar. Análise Psicológica, 3, 411-422.

Sluzki, C. (1996). La red social: Fronteras de la práctica sistémica. Barcelona: Gedisa.

Vitória, T., \& Rossetti-Ferreira, M. C. (1993). Processos de Adaptação na Creche. Cadernos de Pesquisa, 86, 55-64.

Weber, L. N. D., Santos, C. S. D., Becker, C., \& Santos, T. P. (2006). Filhos em Creches no Século XXI e os Sentimentos das Mães. Psicologia Argumento, 24(44), 45-54.

Recebido em: 14/05/2013

Reformulado em: 21/08/2013

Aprovado em: 28/08/2013

\section{Sobre as autoras}

Liana Pasinato (lia.pasinato@yahoo.com.br)

Graduada em Psicologia pela Universidade Regional Integrada do Alto Uruguai e das Missões - URI - Campus de Erechim, Especialista em Psicologia Escolar pelo Centro de Aperfeiçoamento em Psicologia Escolar, Mestre em Psicologia Clínica pela Universidade do Vale do Rio dos Sinos.

Clarisse Pereira Mosmann (clarissepm@unisinos.br)

Professora do Programa de Pós-Graduação e do Curso de Psicologia da Universidade do Vale do Rio dos Sinos. Doutora em Psicologia. 